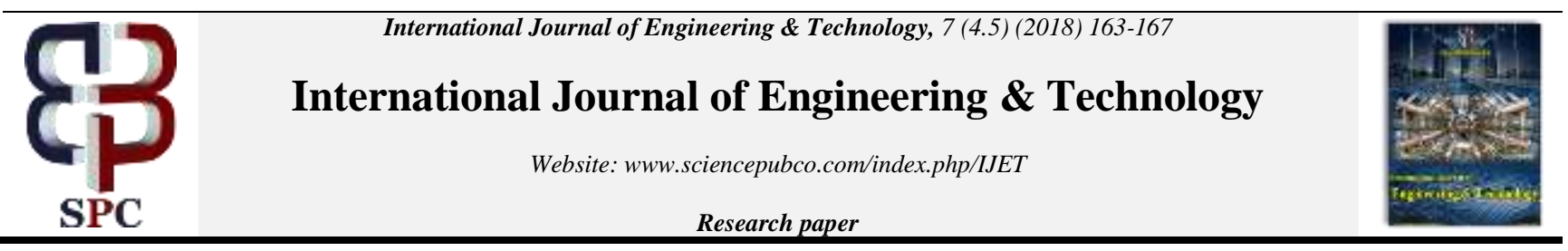

\title{
Reduction of Ripples in A Three Phase Dc-Dc Converter Using Pi Controller
}

\author{
Padmini. ${ }^{1 *}$, Dr.Anupama Prakash ${ }^{2}$ \\ ${ }^{12}$ Department of EEE, Amity University, Noida, Uttar Pradesh. \\ *Corresponding author E-mail: npadhu1996@gmail.com,prakash1@amity.edu
}

\begin{abstract}
The increasing population which in leads to the increase in use of automobiles which constitutes to seventy five percent of carbon monoxide emission. The use of electrical vehicles (EV) has become a necessity to protect the environment from further pollution. The slow charging of the EV is a main hindrance for the success of EV. Fast charging can be achieved by providing charging locations that can be built which can charge the EV in short time span. This paper proposes a bidirectional DC-DC converter with six inverter legs in parallel which is similar to $3 \Phi$ dual active bridge (DAB) converter. This proposed converter has additional inverter legs which increases the converter current capacity resulting in fast charging. A feedback controller is implemented to reduce the ripple content.
\end{abstract}

Keywords: Electrical Vehicle, DC-DC, converter, controller, six leg converters.

\section{Introduction}

Because of the key part that transportation speaks to present day society, the scan for options on its vitality sources has turned into a vital point for both industry and the scholarly community in the course of the most recent decades. The solid reliance on the fuel store network alongside the quick consumption of oil saves [1], a developing natural concern and the persistent ascent in the cost of gas have prompted the improvement of option auto advances (electric, hydrogen, biofuels, and so forth.). Unique consideration has been given to the electric vehicle (EV) idea, as the in all probability substitution to ordinary inside burning motor vehicles, in light of its solid potential to convey standard items for huge scale organization. This is bolstered by considers featuring the benefits of a solid entrance of EVs in the transportation fleet especially as we push toward cleaner power age.

Electrical vehicles can be classified into three types [2], [3]. They are

1. Series Plug in Hybrid Vehicles.

2. Parallel Plug in Hybrid Vehicles.

3. Battery Fed Electrical Vehicles.

Series Plug in Hybrid Vehicles

A Series-PHEV, regularly called an expanded range plug-in hybrid, has an electric engine, battery pack and gasoline generator. The battery pack drives the auto for the begin of the trek. Once the battery is unfilled, the gas generator swings on to broaden the aggregate driving separation. The main distinction between a Parallel PHEV and a Series PHEV is that in a Series PHEV the drivers foot is constantly associated with the electric engine.

Parallel Plug in Hybrid Vehicles

A Parallel-PHEV, frequently called a plug-in hybrid. From the name a parallel-PHEV we can understand that the vehicle has both battery and induction motor set and a gas tank and gas engine set. For the initial distance of $20-40 \mathrm{~km}$ the battery pack and EM drive the auto later the gas engine turns on for longer treks.

Battery Fed Electrical Vehicles

A BFEV, frequently called a completely electric auto, is fueled $100 \%$ by power and never utilizes gasoline.

A comparison in the functions of the ICE vehicle and EV can be made. In a gasoline vehicle the fuel tank serves a source of energy whereas in an EV the same function is performed by the battery. A fuel station is used to refill the fuel in the tank in an ICE vehicle. In an EV a DC-DC charger is used (there are different methods to charge). An ICE vehicle has an engine and an EV has an electric motor (mostly induction motor). An alternator and carburetor are replaced by DC-AC converter and a controller respectively.

\section{CHARGING SCHEMES}

There are four types of charging schemes available for charging the EV battery [4]. They are

1. MODE 1

2. MODE 2

3. $M O D E 3$

4. MODE 4

\section{Dc-Dc Converter}

Generally, off-board chargers are equipped for Vehicles which allow fast charging, [5], [6]; usually direct current (DC) is used in these chargers for charging process, which is normally given by an open utility framework or privately-owned businesses, because of high power levels. 


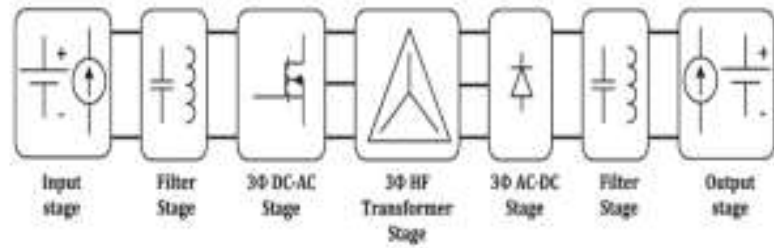

Fig. 1: Block diagram of proposed three phase DC-DC converter

A dual active bridge (DAB) DC-DC converter is in a perfect world reasonable for high power, galvanically disconnected DCDC change. The DAB DC-DC converter has preferences of high power density, bidirectional power exchange ability, a modular and symmetric structure, and simple control prerequisites. The DAB DC-DC converter can likewise be utilized for multi-port operation, which is a component that is valuable in interfacing a few DC sources and loads utilizing a solitary converter.

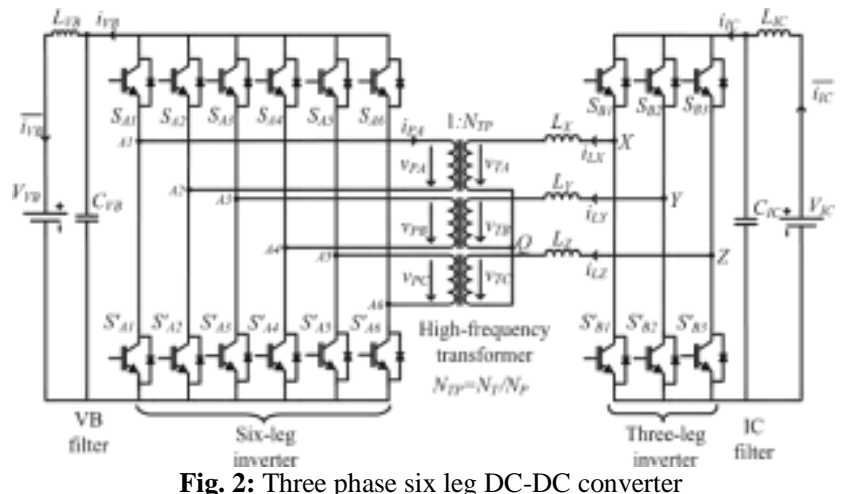

The above proposed circuit [8] is analysed by breaking it down into two independent circuits. The circuit is first analysed as inverter section and then the six-leg converter is analysed. Then both the circuits are coupled by a high frequency transformer and is the total circuit is analysed.

\subsection{Inverter}

The inverter is a circuit that converts DC input into AC output This circuit performs the basic inverter operation which converts the given DC input to the three phase AC output which is a six step VSI. The inverter has six switches which is represented by IGBT. The three-phase inverter can be made to work in $180^{\circ}$ conduction mode or in $120^{\circ}$ conduction mode. In this paper we consider that the inverter is operating in $180^{\circ}$ conduction mode [7].

The total harmonic distortion in the line voltages of the threephase inverter is given by the formula

$$
\begin{aligned}
& \mathrm{V}_{\mathrm{ab}}=\sum_{n=1,3,5}^{\infty} \frac{4 v_{S}}{n \pi}\left[\cos \left(\frac{n \pi}{6}\right) \sin \mathrm{n}\left(\omega t+\frac{\pi}{6}\right)\right] \\
& \mathrm{V}_{\mathrm{bc}}=\sum_{n=1,3,5}^{\infty} \frac{4 v_{s}}{n \pi}\left[\cos \left(\frac{n \pi}{6}\right) \sin \mathrm{n}\left(\omega t-\frac{\pi}{2}\right)\right] \\
& \mathrm{V}_{\mathrm{ca}}=\sum_{n=1,3,5}^{\infty} \frac{4 v_{S}}{n \pi}\left[\cos \left(\frac{n \pi}{6}\right) \sin \mathrm{n}\left(\omega t+\frac{5 \pi}{6}\right)\right]
\end{aligned}
$$

The rms current flowing through the switches is given by

$i_{S B r m s}=\frac{V_{I C}}{2 \Pi f_{c} L_{x}} \frac{\delta}{3} \sqrt{1-\frac{\delta}{2 \Pi}}[\mathrm{A}]$

The average current through each switch is given by

$$
\overline{l_{S B}}=\frac{V_{I C}}{2 \Pi f_{c} L_{x}} \frac{\delta}{3}\left[\frac{2}{3}-\frac{\delta}{2 \Pi}\right][\mathrm{A}]
$$

The peak current through each switch is given by

$i_{\text {SBpeak }}=\frac{V_{I C}}{3 \Pi f_{C} L_{x}} \delta[\mathrm{A}]$

\subsection{Six-leg Converter}

The six-leg converter performs the operation of rectifier. The sixleg converter converts the three phase AC input into DC output. The converter has six legs and each leg has two switches which is represented by IGBT. The IGBTs are named as shown in the fig. 2 . The six-leg converter can be partitioned into three unique phases. Phase A comprises of switches $S_{A 1}, S_{A 2}, S_{A 1}{ }^{1}$, and $S_{A 2}{ }^{1}$. Phase B comprises of switches $S_{B 1}, S_{B 2}, S_{B 1}^{1}$ and $S_{B 2}{ }^{1}$. Phase C comprises of switches $S_{C 1}, S_{C 2}, S_{C 1}{ }^{1}$, and $S_{C 2}{ }^{1}$. Each phase is really a traditional full wave rectifier (bridge connected). The second half of the $\mathrm{DAB}$ is formed by paralleling the three-full wave rectifier each corresponding to each phase. In this way, a similar regulation system utilized for a DAB converter can be used.

Because of the quantity of IGBT, this converter can deal with high streams, with a twofold line-to-line yield voltage, contrasted and a customary three-leg inverter

Identical triggering pulses are utilized for switches $S_{A 1}$ and $S_{A 2}$. Similarly, $S_{A 1}{ }^{1}$ and $S_{A 2}{ }^{1}$ should have a similar triggering pulses. To keep away from a short out of the vehicle battery control source, switches $S_{A 1}$ and $S_{A 1}{ }^{1}$ must have integral triggering pulses. This applies for switches $S_{A 2}$ and $S_{A 2}{ }^{1}$. Remaining phases of the six-leg converter have a similar trademark beforehand depicted for phase A, nonetheless, with a phase shift of $120{ }^{\circ}$ from each other. With this technique, the ripple frequency of the output of the rectifier will be expanded to six-fold the switching frequency, along these lines lessening the measure of the output filter essentially.

The current carried by each IGBT in three-leg inverter is twice the current carried by each IGBT in the six-leg converter. In addition, if a very less voltage is given as an input to six-leg converter then the very high current flows through the IGBTs.

\subsubsection{Advantages of Six Leg Converter}

Real highlights of the converter incorporate [9]- [13]:

a) Paralleling many devices may not increment the power rating, but it is obtained by paralleling phases.

b) By connecting the transformer in delta-wye the output voltage is doubled and hence the turns ratio can be decreased.

c) The size of filter and capacitor at the output and input respectively with interleaved control is reduced.

d) Without auxiliary circuit, zero-voltage zero-current switching

(ZVZCS) is achieved over a wide load run.

Because of these points of interest, it is very suggested in high power applications with high voltage. It is likewise reasonable for other high-power applications with low voltages.

\subsection{Integration of Inverter and Six Leg Converter}

The three legs and six leg converters has been coupled with the high frequency transformer. A DC-DC converter which is capable of handling low voltage and high current extremely difficult. The converter should be prepared to do high-power operation with a high voltage change proportion. A transformer is required for both voltage lift and detachment. In any case, a high turns proportion isn't supported because of conceivably high spillage inductances. Besides, the size of the passive components can be reduced by making the circuit operate in high switching frequency. Soft switching is vital, keeping in mind the end goal to accomplish a high switching frequency while enhancing converter proficiency.

In the circuit proposed the secondary of the transformer is wye connected as this wye connection has the feature of enhancing the output voltage without affecting the turns ratio. Hence the high turns ratio of the transformer is not required. 
The RMS current flowing through each switch is given by

$\mathrm{I}=\frac{v_{i c} \delta}{2 \prod f_{c} l_{x} 3} \sqrt{1-\frac{\delta}{2 \prod}} \quad \mathrm{amps}$

The average current flowing through each switch is given by

$\mathrm{I}=\frac{v_{i c} \delta}{2 \prod f_{c} l_{x} 3}\left[\frac{2}{3}-\frac{\delta}{2 \prod}\right] \quad$ amps

The peak current through each switch is given by

$\mathrm{I}=\frac{v_{i c} \delta}{3 \prod f_{c} l_{x}} \operatorname{amps}$

A filter is connected in the DC input side and the DC output side to filter. The filter is a low pass filter of second order. The filter consists of a capacitor and a inductor. The capacitor and the inductor on the input side is names as $C_{i c}$ and $L_{i c}$ respectively. The current carried by it can be calculated as follows:

$i_{c i c}=i_{c i}-\overline{l_{c l}}$ amps

The design of low pass filter, soft switching operation, power flow in the vehicle batter is discussed in the paper [8].

\section{Closed Loop Operation}

The below block diagram clearly explains the closed loop operation of the proposed three phase dc/dc converter. The name $\mathrm{dc} / \mathrm{dc}$ converter is obtained since because here both the input .i.e, dc source and the output i.e, vehicle battery are dc in nature All paragraphs must be justified alignment. With justified alignment, both sides of the paragraph are straight.

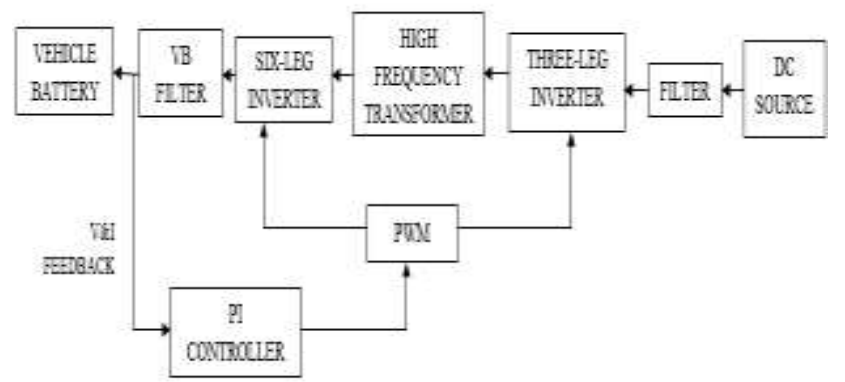

Fig. 3 Block Diagram of Proposed closed loop three phase DC-DC converter

The three phase inverter and six leg converter has been coupled using high frequency transformer and the firing pulses to both three leg inverter and six leg converter is generated using SPWM method. A Proportional Integral Controller has been introduced in the feedback path as shown in fig. 3 to reduce the ripple content in the output dc voltage and in order to obtain steady current for fastcharging of electric vehicles.

\section{Experimental Results}

The inverter circuit can be easily designed in Simulink by appropriately placing the required component and connections. A DC input of 400 volts is given. The load is connected between the load points. Here a suitable RLC load is given to observe the characteristics as the inverter always feeds AC loads which could be resistive, inductive or capacity. The firing pulses are generated for each of the switches using the pulse generator. From the given dc input the required output can be obtained across the load. The waveform can be obtained using the scope module available in the Simulink package.

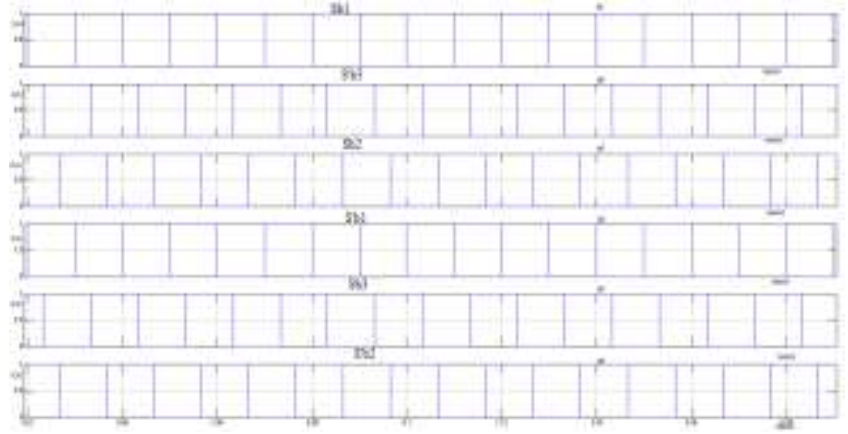

Fig. 4: Gating pulses of three phase inverter

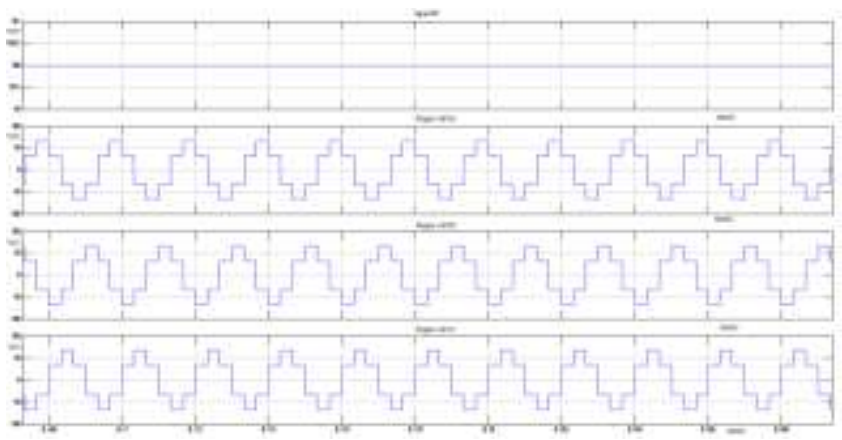

Fig. 5: Output phase voltages of three leg inverter

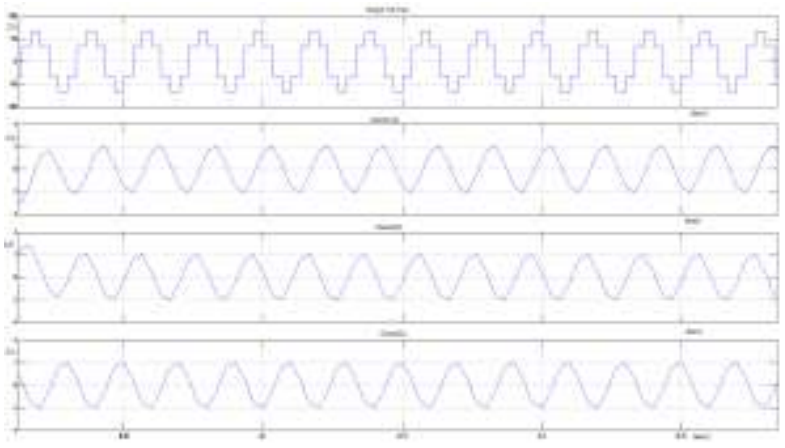

Fig. 6: Output current of three leg inverter

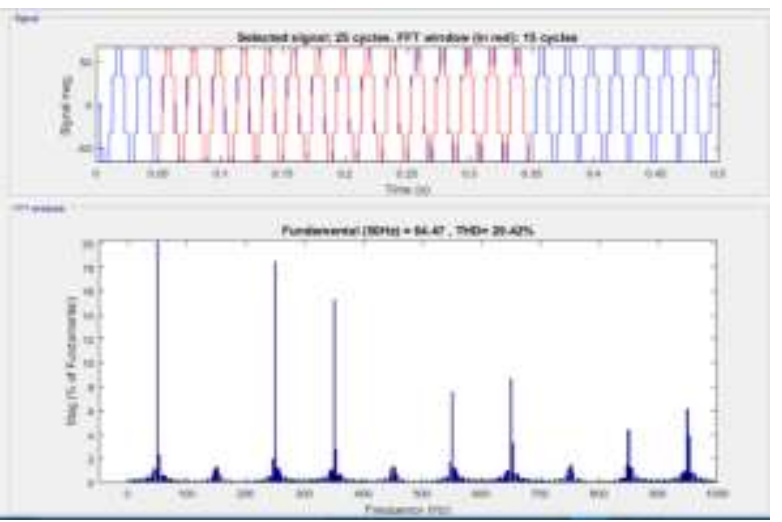

Fig. :7 THD of voltage of three leg inverter

The comparison of current parameters in three leg inverter is shown in table below.

Table I: Comparison Of Parameters Theoretical And Practical

\begin{tabular}{|c|c|c|}
\hline PARAMETER & THEORETICAL(A) & SIMULATION(A) \\
\hline$i_{S B r m s}$ & 3.049 & 3.152 \\
\hline$\overline{l_{S B}}$ & 1.857 & 1.934 \\
\hline$i_{S B p e a k}$ & 6.36 & 6.4 \\
\hline
\end{tabular}

The six-leg converter circuit can be easily designed in Simulink by appropriately placing the required component and connections. An AC input of 100 volts is given. The load is connected between the 
load points. Here a suitable RLC load is given. The firing pulses are generated for each of the switches using the pulse generator. From the given ac input the required output can be obtained across the load. The waveform can be obtained using the scope module available in the Simulink package.

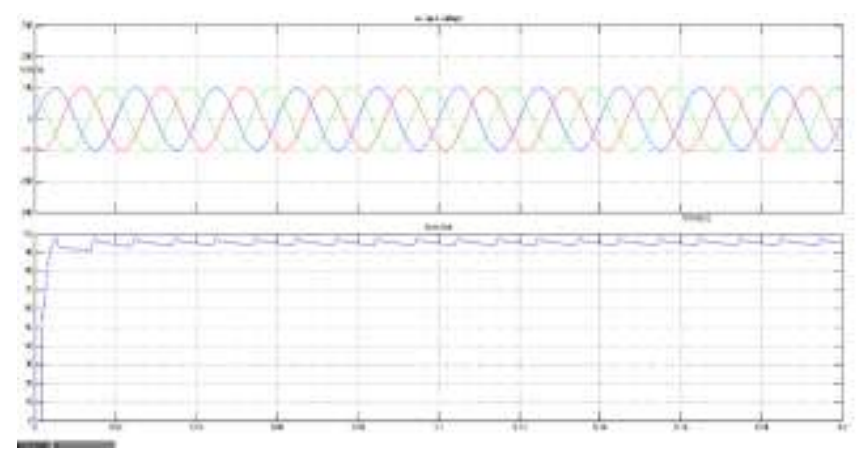

Fig. 8: Input and output of six-leg inverter

After obtaining a favorable output from both converter and the inverter, the next step would be to couple the inverter with the capacitor. The ac output from the three-leg inverter is now fed to the six-leg converter thereby obtaining a DC waveform out of a dc input voltage. From a DC input of $400 \mathrm{~V}$, a DC output of nearly $150 \mathrm{~V}$ was obtained. The resulting AC output from the three-leg inverter is fed to AC loads or connected to the grid. Thus, the proposed DC-DC converter was found to work properly under various load condition.

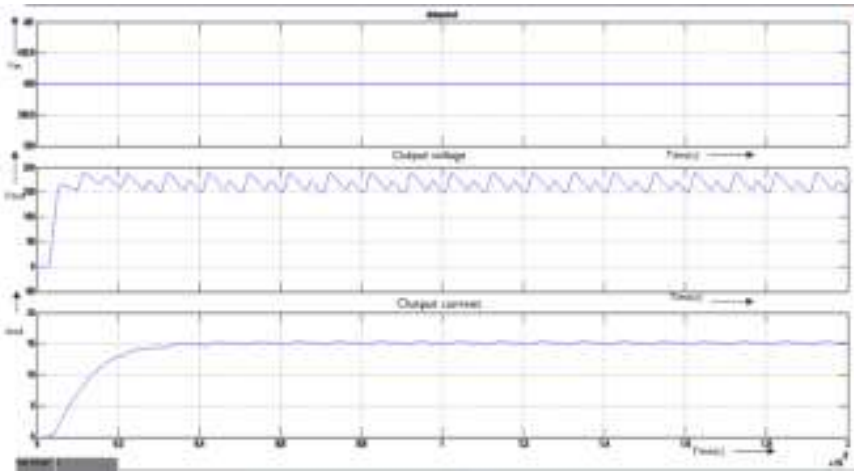

Fig. 9: Input and output waveforms of DC-DC converter

After implementing the feedback PI controller, the outputs of the circuit can be seen as below.

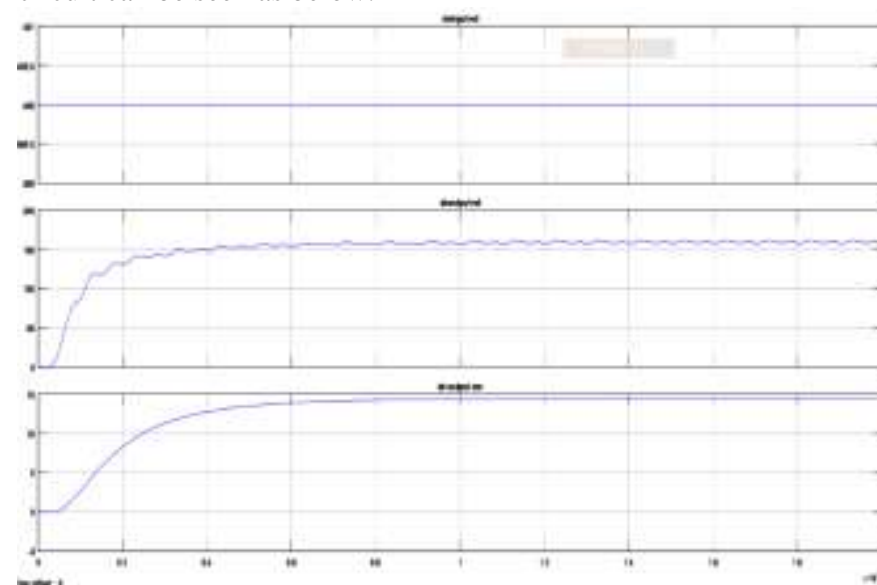

Fig. 10 Input and output waveforms of DC-DC converter with PI controller

With constant input voltage of $400 \mathrm{~V}$, a set of readings were taken with varying resistive loads. The waveforms of output voltage and output current for different resistive loads has been shown

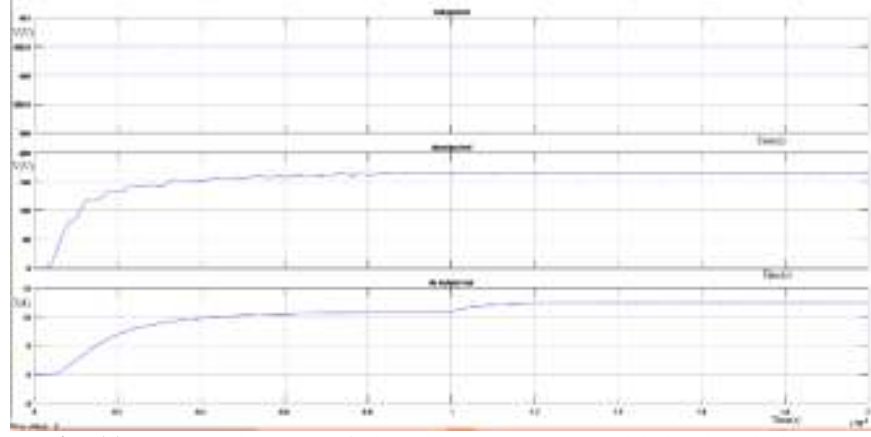

Fig. 11: Input and output of closed loop converter with load variation

The supply voltage is not always constant. Hence the source voltage is varied in small steps from $390 \mathrm{~V}$ to $410 \mathrm{~V}$. It is observed that the output voltage is maintained approximately constant for various values of input voltage.

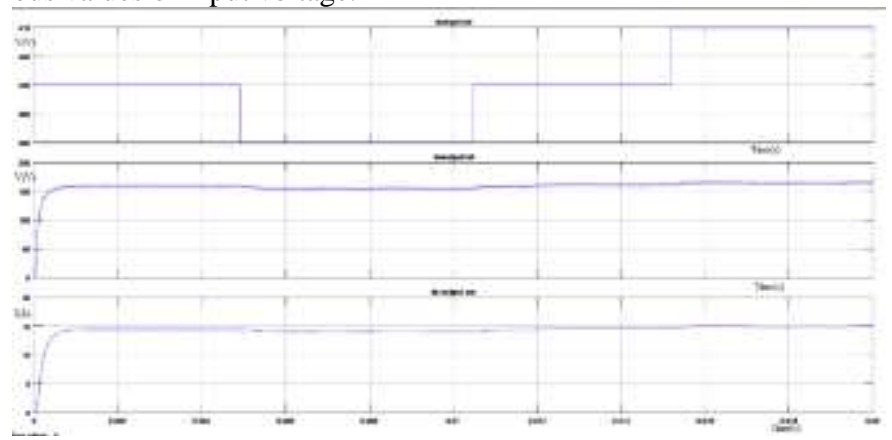

Fig. 12 Input and output of closed loop converter with source variation

\section{Conclusion}

A Three phase DC/DC converter with six inverter legs in parallel which can deliver high current output suitable for charging the battery of electrical vehicle (EV) is proposed in this paper. During the forward operation the circuit works in buck mode of operation so that the current increases to a desirable value enabling DC fast charging of the battery.

During the reverse operation battery which is at a lower voltage level acts as source so the converter operates in boost mode of operation reaching the DC voltage level at the input.

By using the proposed circuit, the following benefits are obtained 1. By increasing the number of parallel phases on the converter side the power capability on either side of the circuit increases which further enables to handle higher power enabling DC fast charging.

2. By using the circuit in forward operation the value of the output current is increased considerably which reduces the time required for charging the EV battery.

3. By implementing a Proportional Integral (PI) controller the amount of ripple is reduced by a large amount which enhances the state of charging i.e. the overall lifecycle of the battery.

4. The performance of the circuit is verified by doing load and source variations.

\section{References}

[1] J.P Painuly, "Barriers to renewable energy penetration; a framework for analysis", Renewable Energy Vol 24,Pp 73-79,2001.

[2] Ali Emadi, Young Joo Lee, Rajashekara, "Power Electronics and Motor Drives in Electric, Hybrid Electric, and Plug-In Hybrid Electric Vehicles", IEEE TRANSACTIONS ON INDUSTRIAL ELECTRONICS, VOL. 55, NO. 6, JUNE 2008

[3] C. C. Chan and Y. S. Wong, "Electric vehicles charge forward," IEEE Power Energy Mag., vol. 2, no. 6, pp. 24-33, Nov./Dec. 2004

[4] Murat Yilmaz and Philip T. Krein," Review of Battery Charger Topologies, Charging Power Levels, and Infrastructure for Plug-In 
Electric and Hybrid Vehicles", IEEE TRANSACTIONS ON POWER ELECTRONICS, VOL. 28, NO. 5, MAY 2013

[5] C. Botsford and A. Szczepanek, "Fast charging vs. slow charging: Pros and cons for the new age of electric vehicles," inProc.Int.Battery, Hybrid Fuel Cell Elect. Veh. Symp., May 2009, pp. 1-9.

[6] S. Kim and F. Kang, "Multi-functional on-board battery charger for plug-in electric vehicles," IEEE Trans. Ind. Electron., vol. 62, no. 6, pp. 3460-3472, Jun. 2015.

[7] P.S.Bhimbhra," Power electronics", Khanna publications, $4^{\text {th }}$ edition, 2012.

[8] Gierri waltrich, Marcel A.M.Hendrix , Jorge L.Duarte, “ Three phase bidirectional DC-DC converter with six inverter legs in parallel for EV applications" Published in IES power electronics ,2016.

[9] C. Liu, A. Johnson, and J.-S. Lai, "A novel three-phase high-power softswitched dc/dc converter for low-voltage fuel cell applications," IEEE Trans. Ind. Appl., vol. 41, no. 6, pp. 1691-1697, Nov./Dec. 2005.

[10] R. De Doncker, D. Divan, and M. Kheraluwala, "A three-phase soft-switched high-power-density dc/dc converter for high-power applications," IEEE Trans. Ind. Appl., vol. 27, no. 1, pp. 63-73, Jan./Feb. 1991.

[11] A.Kuperman, U. Levy, J.Goren, A.Zafransky, andA. Savernin, "Battery charger for electric vehicle traction battery switch station," IEEE Trans. Ind. Electron., vol. 60, no. 12, pp. 5391-5399, Dec. 2013.

[12] B. Zhao, Q. Song, W. Liu, and Y. Sun, "A synthetic discrete design methodology of high-frequency isolated bidirectional $\mathrm{dc} / \mathrm{dc}$ converter for grid-connected battery energy storage system using advanced components," IEEE Trans. Ind. Electron., vol. 61 Oct. 2014

[13] Z. Wang and H. Li, "A soft switching three-phase current-fed bidirectional dc-dc converter with high efficiency over a wide inpu voltage range," IEEE Trans. Power Electron., vol. 27, no. 2, Feb. 2012. 